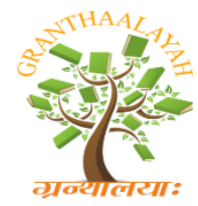

INTERNATIONAL JOURNAL OF RESEARCH GRANTHAALAYAH A knowledge Repository

Social

\title{
A STUDY OF PARTS OF SPEECH USED IN ONLINE STUDENT WEEKLY MAGAZINE
}

\author{
Sukanya Khaisaeng $^{* 1}$, Nutprapha K. Dennis ${ }^{2}$ \\ ${ }^{*} 1,2$ English Department, Graduate School, Ubon Ratchathani Rajabhat University, Thailand
}

DOI: https://doi.org/10.29121/granthaalayah.v5.i4.2017.1793

\begin{abstract}
The purpose of this study was to analyze the frequency of parts of speech from online Student Weekly Magazine. The setting and material of the study were 30 education news articles in seven levels from the website http://www.studentweekly.com from the 1st of October 2015 to the 30th of November 2015. The study focused on parts of speech; noun, pronoun, verb, adverb, adjective, preposition, determiner and conjunction. The data collection and analysis used frequency and percentage. The research findings showed that there were 7,800 words to analyze for parts of speech from the 30 news articles. It found that of the 7,800 words there were 3,112 nouns 3,112 equaling (40\%), 1,347 verbs equaling (17\%), 1,028 prepositions equaling (13\%), 829 determiners equaling (11\%), 708 adjectives equaling (9\%), 338 pronouns equaling (4\%), 232 adverbs equaling (3\%), and 206 conjunctions equaling (3\%). In conclusion, education news in an online Student Weekly Magazine used more nouns than other part of speech with 40\%, and the lowest percentage was conjunctions for only $3 \%$.
\end{abstract}

Keywords: Online News; Education News; Parts of Speech.

Cite This Article: Sukanya Khaisaeng, and Nutprapha K. Dennis. (2017). "A STUDY OF PARTS OF SPEECH USED IN ONLINE STUDENT WEEKLY MAGAZINE." International Journal of Research - Granthaalayah, 5(4), 43-50.

\section{Introduction}

English is a universal language since many countries use it as an official, second or foreign language. English in Thailand is considered a foreign language which students have to learn at school. Nowadays, English has been pushed by Thai government to be a very important part of the education system. English subject in Thai school curriculum requires students at all levels to study English as a foreign language beginning from the elementary level to the tertiary level. Even though Thai students study English for many years, many are not successful in being able to use English proficiently. In teaching English, there are four skills of the language: listening, speaking, reading and writing that must be taught. In addition to those four skills that language learners to succeed in learning, they must also have background knowledge of vocabularies. 
Russell (2006) mentions that the students' listening, speaking, reading and writing ability will be developed through words and that the students who have better listening, speaking, reading and writing abilities, tend to have more vocabulary knowledge. In the other words, the students have to recognize or recall the meaning of words in order to understand the passage or context of reading or listening. The main purpose of all English courses is to enable students to gain more knowledge for their future careers and higher education. However, the outcome of students' learning remains unsatisfactory. Students are still having difficulties mastering or even improving their four main language skills. The evaluation revealed their low proficiency in pronunciation, grammar and knowledge of parts of speech. Parts of speech knowledge is an important subject area that students should know. Parts of speech are one of the important components in studying any language. Parts of speech help students and learners to understand and use the target language more efficiently. Some learners cannot listen, speak, read or write English effectively if his/her parts of speech knowledge is limited. This problem seems to obstruct his/her learning of English because parts of speech are an important element in the acquisition of a second language.

The researcher has been teaching English to grade 9 students at The Third Samakkee Wittayakan Municipal School, Ubon Ratchathani and found that the students' rating in English proficiency is considered to be at a low level. The researcher asked the students about their problems in learning English and they said that although they like to study English, they are confused about the parts of speech which they have learned. Therefore, they were bored in learning because they were unable to recognize the parts of speech. Thus, the researcher tried to study the research and documents about teaching English parts of speech to find strategies to improve the students' and learners learning. We know that some students and learners come to their studies with varying levels of background knowledge in learning strategy use and that all students and learners can benefit from improving their learning strategies.

An online Student Weekly Magazine is one of the materials that the researcher used in a simple but effective way for students and learners. It is a good choice because it is quick, powerful, and it offers an unlimited list of free downloadable and useful sites for students and learners to improve their reading skills, while having great fun learning English successfully.

\subsection{Purpose of the Study}

The purpose of this study is to analyze the frequency of parts of speech used in an online Student Weekly Magazine.

\subsection{Scope of the Study}

In this study the researcher selected 30 education news articles from an online website at http://Studentweekly.com, each news article that contained 140- 555 words are analyzed. The study focuses on categorizing parts of speech that exist in the news and analysis of usage frequency and percentage of part of speech. 


\subsection{Significance of the Study}

The finding from this research will be beneficial as follows:

- The findings in this research will be beneficial for Thai students who would like to learn English by themselves through online Student Weekly Magazines because there were many activities to learn such as education news, entertainment, horoscope, and comic. They could learn by reading and following the education news. They can practice reading skill by reading English news.

- The finding may be useful for English teachers who would like to teach all skills by using online news as their teaching resource.

- This finding might be beneficial for interested people or other language learners, educational institutions and practitioners to develop the use of the English language. Moreover, it is also a guideline language policy makers for curriculum design.

\subsection{Previous Studies}

According to Potiantong (2010), the result of the study showed the genre move structure and lexicon-grammatical features of main dish recipes. 40 recipes are selected and analyzed from one English cookbook. The result of the study shows that; noun is the mostly used part of speech in recipe writing $(44.018 \%)$ while pronoun is the least used part of speech found from the study $(0.355 \%)$. The move structures of the recipes are: Introduction, Recipe Name, Relate Information, Ingredients Part, Cooking Instruction, Additional guidance, and Side Dish Recipe. In conclusion, the recipe writing is unique unlike other type of writing. The style of recipe writing is shaped by the structure that each part separated and can be seen clearly. The imperative sentences are popularly used in this kind of writing more than any other kind of sentence.

Chusrikul (2008) surveyed of English vocabularies of grade 6, grade 9 and grade 12 students 2008. The purposes of this research were to survey English vocabularies of grade 6, grade 9 and grade 12 students, to classify these vocabularies in two alphabetical A-Z groups, and to specify their parts of speech and word classes. For their parts of speech, it was found that most of grade 6 students' vocabularies i.e., 1,343 words $(63.98 \%)$ were nouns, while the least of them i.e., 11 words $(0.52 \%)$ were pronouns. For grade 9 students' vocabularies, most of them i.e., 1,763 words $(55.21 \%)$ were also nouns, but the least of them i.e., 5 words $(0.16 \%)$ were interjections. Moreover, most of grade 12 students' vocabularies i.e., 1,674 words (50.51\%) were nouns, but the least of them i.e., one word $(0.03 \%)$ was a pronoun.

The purpose of Pumpang (2012) study is to analyze the types of adjectives and adjective functions in a noun phrase found in an online news site "The Jakarta Globe". Online news is very well known in all circles, both among young people and adults, because the news was very easy to access. The information and latest news provided by the online news website can be published in a very quick time, without waiting for a longer period of time, just a few minutes were enough to gain all information for the interested users. This study uses the qualitative method, as well as the best possible literature method. The theory which is used as a reference in this research is a theory about types of adjectives by AJ Thomson and A.V. Martinet in his book with the title: "A Practical English Grammar Use", plus the theory of functions of word properties by Qurik in his 
book with the title: A Comprehensive Grammar of the English Language. The results of this study indicate that there are six types of adjectives in the British language: demonstrative adjectives, distributive adjectives, quantitative adjectives, interrogative adjectives, possessive adjectives, and adjectives of quality, as well as three function words properties in a noun phrase: attributive functions, postpositive functions, and adjectives as "the head of the noun phrase".

Surin (2005) focused on the use of English in cosmetic advertisement headlines and the samples were analyzed in three aspects: the vocabulary use, the grammatical structure and the types of headlines. The result showed that "nouns" were mostly employed in headline writing. Based on all word frequency, the study also indicated that the adjective "new" is the word that is most frequently used. There are five types of grammatical structures used. The two most popular types are "fragment" and "simple sentence" respectively. In respect to the types of headlines, direct benefit headlines are mostly found.

Suvaree (2006) studied about language of advertising has long been studied in various aspects, but little research has been undertaken on airline advertisements. In this study, some major figures of speech and persuasive techniques of advertising claims found in 50 advertisements from 43 airlines are thoroughly examined. Besides the genre of airline advertisements, this study will be focusing on the move structure is also analyzed. It was found that the most frequently used figure is alliteration, while the least used is simile. The trend of using figures showed that those related to sound repetition and without meaning change were more popular than those related to comparison and substitution, due to the former having less complexity and no need for interpretation. For advertising claims, the "Scientific or Statistical" Claim was the most often used while the "Water is Wet and So What" Claim was used least. The result suggested that the claims offering some kind of clear convincing evidence are employed more than those without, as this helps advertisements to be more believable. For the genre analysis of the airline ads, there are only four ads that contain all six moves: Calling Attention, Creating Interest with Advantages, and Asking for Order, as they are most frequently found in the top three ranks and considered to be crucial for achieving the persuasive purpose of airline ads.

From researching the document and the studies above, the researcher is interested in using online websites to develop the learning English ability of primary school students in an effective way.

\section{Materials and Methods}

The study focused on analyzing context to eight categories of English parts of speech ; Noun, Pronoun, Adjective, Adverb, Verb, Preposition, Determiner and Conjunction usage toward online Student Weekly Magazines. The data from this study was quantitative.

\subsection{Setting and Material of the Study}

The selected education news in this study was from Student Weekly an online magazine (http://www.Studentweekly.com/). The selected section for this study was about thirty education news articles - as the news from the $1^{\text {st }}$ of October 2015 to the $18^{\text {th }}$ September 2015 . The researcher chose Student Weekly to study because the texts were free, could copy in Microsoft Word and referenced them, classroom handouts were readily reproducible, interactive, and 
printable English lessons from elementary to advanced. A list of education news; 1. Money Measures, 2. Healthy Kids,3. One and Only, 4. Katrina Remembered, 5. Spiritual Sounds, 6. Class Control, 7. Traditional Moves, 8. Eastern Delights, 9. Landslide Loss, 10. Little Hosts, 11. Flyover Over, 12. Scenic Satun, 13. Endless Loop, 14. Mosqoe Mob, 15. Top Ranking, 16. Festive Procession, 17. Wonderful Wuzhen, 18. Wild Nights, 19. Fighting the Haze, 20. High Flyers, 21. Overstay Overreaction, 22. High Season, 23. Sugar Rush, 24. Hit the North, 25. Social Science, 26. Bangkok Beauty, 27. Temporary Friends, 28. Vampire Weekend, 29. Pitch Perfect, 30. Trade Ties.

\subsection{Research Instrument}

The research instrument in this study was a checklist which determines and categorizes English part of speech in eight aspects; Noun, Pronoun, Adjective, Adverb, Verb, Preposition, Determiner and Conjunction from each news.

\subsection{Research Procedures}

The procedures of data analysis of this study were explained below.

- Step 1: Analyze the news by categorizing the sentences used in news writing into groups according to the structure of part of speech, which are divided into eight sub-categories; Noun, Pronoun, Adjective, Adverb, Verb, Preposition, Determiner and Conjunction.

- Step 2: Categorize the analyzed data.

- Step 3: Compute the percentage to get the frequencies of each sentence.

- Step 4: Analyze the data and make the conclusion and discussion.

According to the analysis, the following data is the result of the frequency of part of speech found in the selected news.

\subsection{Data Collection and Analysis}

Thirty English news articles were collected from the selected website: StudentWeekly.com. The target news articles contained a pre-determined range of sentences and a word count. According to the information that the good news should be concise and not too long but easy to understand and follow. The education news articles with a word count between 140-555 words are a good length, which is randomly calculated from the online news. After the collected data had been categorized, the researcher analyzed all the data in percentage with computer program of Microsoft Excel to find out the frequency of each category and conclude the results with clear and concise explanation.

\section{Results and Discussions}

The analysis of education news's student weekly were summarized and presented by frequency and percentage of parts of speech, from table four point one to table four point thirty that only covered nouns, pronouns, verbs, adverbs, adjectives, prepositions, determiners and conjunctions. 
According to Potiantong (2010) the result of the study showed the genre move structure and lexicon-grammatical features of main dish recipes. 40 recipes were selected and analyzed from one English cookbook. The result of the study shows that; noun is the mostly used part of speech used in recipe writing at a usage percentage of $(44.018 \%)$ while pronoun is the least used part of speech as found from the study at a usage percentage of $(0.355 \%)$. The move structures of the recipes are: Introduction, Recipe Name, conclusion, the recipe writing is unique unlike other type of writing. The style of recipe writing Relate Information, Ingredients Part, Cooking Instruction, Additional guidance, and Side Dish Recipe. In is shaped by the structure that each part separated and can be seen clearly. The imperative sentences are popular used in this kind of writing more than other kind of sentence.

The results showed that the frequencies and percentages of eight parts of speech in an online news source titled, "Student Weekly Magazine" from the total word count of 7,800 words. Noun was the most used with a total word count of 3,112 words which is a percentage of $(40 \%)$, verbs total use is 1,347 words with a percentage of $(17 \%)$, prepositions used a total of 1,028 words with a percentage of (13\%), determiners accounted for 829 words with a percentage of (11\%), adjectives used 708 words with a percentage of $(9 \%)$, pronouns used 338 words total which is a percentage of (4\%), adverbs used only 232 words with a mere (3\%) as follows:

Education news in an online news source titled, "Student Weekly Magazine" used noun with a total word count of 3,112 words with (40\%); for example "tests", "exams", "tips", "entrance", "examination", "Vampire", "weekend", "selfie", "party", and "Tokyo", etc. Verb used a total 1,347 words with (17\%); for example "is", "help", "prepare", "answer", "escaping", "take", "wound", "leaving", "entered" and "suffered", etc. Preposition used total 1,028 words with (13\%); for example "by", "of", "for", "from", "in", “on", "inside", "of", "at" and "during", etc. Determiner used a total 829 words with (11\%); for example "a", "an", "the", "this", "that", "those", "which", "all" and "some", etc. Adjective used a total 708 words with (9\%); for example "perfect", "similar", "former", "late", "first", "critical", "live", "first-degree", "restive" and "captive", etc. Pronoun used a total 338 words with (4\%); for example "you", "your", "it", "him", "my", "its", "their", "they", "he", "his", "who", "them", "her", and "us", etc. The adverb total was 232 words with (3\%); for example "here", "also", "then", "not", "previously", "mainly", "now", "currently", "nearly" and "again", etc. In contrast, education news in an online news source titled, "Student Weekly Magazine" conjunction use had the least word count total with 206 words with (3\%); "and" (showed 191 times), "but" (showed 9 times), and "or" (showed 6 times). In conclusion, education news in an online new source titled, "Student Weekly Magazine" used noun more often than verb, adverb, adjective, preposition, determiner, pronoun and conjunction. Almost all types of parts of speech, the highest percentage was noun that was used most frequently with a total word count of 3,112 words with (40\%) and the least percentage was conjunction that was used 206 times with (3\%).

\section{Conclusions \& Recommendations}

The purpose of this research was to study parts of speech used in 30 education news articles from an online Student Weekly Magazine Website. This study analyzed English parts of speech in eight categorizes: noun, pronoun, verb, adverb, adjective, preposition, determiner, and conjunction which were used the first of October in 2015 to the thirtieth of November in 2015. 
Nowadays many people are very familiar with StudentWeekly.com. The analysis on those based mostly on frequency and percentages. This study was a survey research. The data collection was from 30 selected education news articles from StudentWeekly.com. The researcher managed the use of data analysis by using the frequency and percentage of various types of parts of speech as a tool to use English language teaching resources more efficiently. In the results, parts of speech was divided into eight categorizes in an online education news site titled: "Studentweekly.com" with the summarization of the frequent usage of parts of speech from 30 education news articles in an online news source titled, "Student Weekly Magazine". The percentages of the result were based on a total word count from the 30 articles of 7,800 words as follows:

The research instruments included 1) 30 education news articles in an online news source titled, "Student Weekly Magazine" 2) Eight English parts of speech: noun, pronoun, verb, adverb, adjective, preposition, determiner and conjunction. The data collected was analyzed by using "http//:parts-of-speech.info.com" to classify the eight parts of speech and "Microsoft Excel" was used to analyze frequencies and percentages. The research result was as follows: It was found that the noun had a highest frequency with a total of 3,112 words and in contrast the lowest frequency was conjunction that used a total of 206 words.

\subsection{Recommendations}

The findings in this study are beneficial for students and learners who have an interest in learning English language by themselves because of clarity the sentences used which contributes to an ease of understanding, and the saving of time and money needed to invest in learning English language by using Student Weekly Website.

\subsection{Recommendation for Present Study}

- The analysis is useful for learners to increase understanding and permanent long term memorization of parts of speech used in online news and enabling them to read online English news more easily without the pressure having a teacher behind him or her.

- The analysis is useful for teachers who using online news to teach English parts of speech, they can easily use this case study as their teaching resource to enhance learners' educational outcome intensively.

- Other materials such as movies, songs, tales, newspapers, advertisements, etc. should be considered to study as well.

- The scope of study could be broadened to include a larger material of online news to get more details.

\subsection{Recommendation for Further Study}

- A study of English grammar; English parts of speech in studentweekly.com which studies English education news.

- A study of English grammar; English parts of speech used in news in other website such as Bangkok Post, Breaking News, VOA, and BBC News, etc. 


\section{References}

[1] Chusrikul, N. A. (2008). A Study of English Grammar Skill of Thai Employees in A Private Company: A Case Study of Sony Mobile Electronic Thailand Co.Ltd. Master of Arts Independent Study.

[2] Potiantong, K. A. (2010). A Genre Analysis of the Main Dish Recipe. Master of Arts Independent Study.

[3] Pumpang, K. (2012). English Usage in House Advertisement from a Webpage: A Case Study. Master of Arts Independent Study.

[4] Russell, D. H. (2006). Children Learn to Read. New York: Ginn, 2006.

[5] Surin, B. (2005). The Analysis of English Usage in Cosmetic Advertisement Headlines. Master of Arts Independent Study.

[6] Suvaree, P. (2006). The Study of Language Use in Airlines' Advertisements. Master of Arts Independent Study.

\footnotetext{
*Corresponding author.

E-mail address: nootprapa@gmail.com
} 